\title{
Acceso y transmisión de la información en las primeras guerras del S.XXI
}

\author{
Access and information transfer in the first wars of the XXI century
}

\author{
Dra. Rosana Fuentes Fernández \\ Universidad San Jorge (USJ) \\ rfuentes@usj.es
}

Recibido: 30 de noviembre 2011

\section{Resumen}

Aceptado: 29 de diciembre 2011

El presente trabajo es un estudio de las habilidades que desarrollaron los periodistas en las primeras guerras del siglo XXI para acceder a la información y enviarla a su medio. Se realizó una investigación cualitativa de fuentes primarias que procedieron de 15 entrevistas en profundidad y secundarias que partieron de 25 crónicas en prensa desarrolladas por Alfonso Rojo en la Guerra del Golfo y la invasión de Irak, Juan Cierco durante la Segunda Intifada, Gervasio Sánchez en la Guerra Civil en Sierra Leona y Ángeles Espinosa en la "caída" de los talibán. El análisis tiene como objetivo conocer cuáles son las prácticas no ortodoxas empleadas, cómo se ganan a las fuentes o salvan la censura, cuáles son los cebos informativos empleados, si abusan de las informaciones indirectas o cómo acceden a las transmisiones.

\section{Abstract}

This work is a study of the skills developed in the first journalists century wars for access to information and send it to their media. We conduced a qualitative investigation of primary sources that come from 15 interviews and 25 secondary press chronics developed by Alfonso Rojo in the Gulf War and the invasion of Iraq, Juan Cierco during the Second Intifada, Gervasio Sánchez in the Civil War in Sierra Leona and Ángeles Espinosa in the taliban's "fall". Analisys aims to censorship, what news baits employees, if the abuse the indirect information or how to access the broadcasts. 
Palabras clave: Habilidades, acceso a la información, transmisiones, censura, cebos informativos, informaciones indirectas.

Key words: Skills, access to information, broadcasts, censorship, news baits, indirect information.

Sumario: 1. Introducción. 2. Metodología. 3. Resultados. 3.1. Ganarse a las fuentes. 3.2. Salvar la censura de los guías-espía. 3.3 Cebos informativos. 3.4. Informaciones indirectas. 3.5. Prácticas no ortodoxas. 3.6. Acceso a las transmisiones. 4. Conclusiones. 5. Bibliografía.

Summary: 1. Introduction. 2. Methodology. 3. Results. 3.1. Earning to sources. 3.2. Save the censorship of the interpreters-spies. 3.3. Baits information. 3.4. Indirect information. 3.5. Not recommended practices. 3.6. Access to transmission. 4. Conclusions. 5. Bibliography.

\section{Introducción}

La dificultad para informar desde los países en conflicto, acceder a las fuentes de información o la censura a la que están expuestos los periodistas les obligan a recurrir a salvoconductos, ganarse a las fuentes o buscar alternativas a las informaciones oficiales. Habilidades que les permiten finalmente acceder a los datos y lograr transmitirlos a su medio de comunicación como analizamos en las crónicas de Alfonso Rojo durante Guerra del Golfo de 1991 y la invasión de Irak de 2003, en el trabajo como freelance de Gervasio Sánchez en la Guerra Civil en Sierra Leona de 1999-2001, la corresponsalía de Juan Cierco en la Segunda Intifada de 2000 y la cobertura de Ángeles Espinosa durante la "caída" del régimen talibán en 2001.

Los gobiernos de los países en guerra suelen crear ministerios de información para controlar o dificultar la tarea informativa. Los periodistas que escribieron sobre Oriente Próximo en el transcurso de los dos años que van de 2000 a 2002 lo hicieron bajo coacción. Dray y Sieffert indican que no todas las presiones fueron iguales por lo que distinguen entre el condicionamiento psicológico, la polémica y la intimidación (2004: 171).

En la invasión de Irak de 2003, los tres funcionarios al cargo del Ministerio de Información fueron Kadum, Kasem y Al Taj. Censores que trabajaban sin sutilezas, medias tintas o ambigüedades. La censura en estado puro. Como nunca la habían sufrido los periodistas. Un cercenamiento absoluto de su libertad de expresión que poco a poco fueron aprendiendo a sortear (Sistiaga, 2004: 121). La llegada masiva de reporteros a Bagdad dejo al Ministerio de Información sin tutores para controlarlos. Los enviados especiales fueron obligados a unirse 
a otros compañeros de profesión para compartir los guías. Lo hicieron sobre todo con reporteros de radio o de prensa, pero no con las televisiones, "sobre las que pusieron un especial mimo por controlarlas" (121).

La Autoridad Provisional de la Coalición también intervino la información a través de su Administrador, Paul Bremen, que debido al aumento de periodistas se vio obligado a emitir una normativa en forma de nota pública (conocida como el decreto nำ14) en la que se regulaba la actividad de los medios de comunicación. Incluía una serie de secciones en las que se determinaba, según Gutiérrez de Terán, qué tipo de contenidos podían conducir a la clausura de un medio de comunicación como aquellos que incitaran a la desobediencia civil o la violencia contra grupos raciales, religiosos, la mujer y las fuerzas de la Coalición; o aquellos que propugnaran el regreso del partido Baaz o incluyeran declaraciones que pretendiesen representar su ideario político:

Estas condiciones, en primer lugar la de no incitar a la violencia contra las tropas aliadas, no dejan de estar abiertas a interpretaciones particulares, ya que un reportaje periodístico que enumere todas las consecuencias negativas derivadas de la ocupación militar puede considerarse como susceptible de fomentar una reacción hostil o la desobediencia civil por parte de los lectores (Hijazy y otros, 2003: 136).

El siguiente obstáculo que a menudo se encuentran los reporteros es la información sesgada debido a la desproporción entre los bandos enfrentados tanto por el territorio como por las armas. En la Segunda Intifada, la parcialidad informativa empezó cuando se rechazó el papel que desempeñó la provocación de Ariel Sharon en el desencadenamiento del conflicto. Dray y Sieffert indican que, como toda la prensa, la AFP: "Reveló la estrecha correlación que había entre ambos acontecimientos. Todas las apariencias y la evolución de los acontecimientos a partir del 29 de septiembre de 2000 apoyaron dicha tesis" (2004: 180).

Las fuentes de información tampoco colaboran de igual manera con los periodistas. En los conflictos, las militares y policiales suelen estar más dispuestas a aparecer en los reportajes en directo de los periodistas o mostrar su potencial armamentístico como un capitán de artillería rusa que le propuso a Robert Fisk abrir fuego con las ametralladoras. Fisk confiesa que estuvo tentado a decir que sí, pero al imaginar el desmembramiento de un cuerpo anónimo, corrió tras él y le dijo que no debía disparar en ninguna circunstancia (2005: 270).

Los periodistas en general tienden a entrevistarse con los oficiales, ya que los altos cargos son más "políticos". Alfonso Bauluz se decantó por los marines hispanos, los más próximos a los abonados de Efe. En su unidad había 140 marines en la compañía 117 CSSG (Compaq 
Support Service Group). Él se encontraba con un grupo de unos 30 marines. Cuando un sargento de marines contaba lo mismo que otros periodistas, se podía pensar que era verdad lo que detallaba, y se ponía "según fuentes militares" (2008).

La dificultad para contactar con fuentes ajenas a las oficiales se suple en algunos conflictos con la petición de salvoconductos a las embajadas o a sus diplomáticos para moverse libremente por el territorio en guerra. Algunos periodistas recurren a fuentes que luego no identifican o a rumores. La llegada de un gran número de enviados especiales facilita el acceso a las fuentes en la zona de conflicto. Sin embargo, puede provocar que la gente reaccione de manera distinta a como lo harían normalmente, poniéndose a llorar o dramatizando.

Los regalos para aprovechar las debilidades de los censores y pasar sus noticias es una práctica común en el periodismo que tiende a "engrasar" las fuentes. Carlos García-Santa Cecilia recuerda una anécdota de Herbert Matthews que recrea Arturo Barea en una de sus crónicas sobre la Guerra Civil española. Matthews dijo al censor que quería pasar a su editor una cuenta de gastos contra los sabañones (las condiciones de vida eran duras) y para demostrar que no se trataba de una clave, mostraba el sabañón en la punta de su nariz (2008).

La obtención de visados tampoco es una tarea fácil para los periodistas. Conseguir un visado para entrar en el Golfo podía costar semanas por eso los enviados especiales tuvieron que ingeniárselas de distintas formas. La negativa de Arabia Saudí para conceder uno a Robert Fisk tras la invasión de Irak hizo que entrase agachado en la cabina de un avión 707 de la MEA con destino Dhahran. Joe Kai, miembro del personal de estación en Beirut de la aerolínea, se dio cuenta de que incluso sin visado un pasajero de la MEA tenía derechos de circulación en Arabia Saudí, siempre que tuviera un billete con escala en otro Estado del golfo Pérsico. De esa forma, Fisk entró en Barhéin y ayudó a The Independent a dar la primicia mundial de la presencia de los estadounidenses (2005: 815).

Salir durante horas no permitidas y con traductores no oficiales por el país en guerra es igualmente peligroso. En Irak, los periodistas tuvieron que emplear distintas tácticas para lograr informar. Robert Fisk cuenta cómo un día cogió un taxi y al pedirle al conductor turco que encendiese la luz piloto del interior del coche, una patrulla de soldados de las fuerzas especiales turcas se abalanzó hacia ellos con las escopetas al hombro:

En esas circunstancias, yo solía interpretar el papel de 'británico escandalizado'. Puse los brazos en jarra y grité: ‘¿Qué demonios pasa aquí?’. 
Un oficial se acercó a mí y yo le extendí la mano. Es una forma segura de aliviar la tensión entre soldados furiosos. Pese a lo enfadado o asustado o borracho que esté, ningún oficial se humillaría negándole el saludo a un extraño perfectamente amistoso. El soldado se pasó la escopeta a la otra mano para estrechar la mía, sonrió y preguntó, con un inglés absolutamente impecable: ‘¿Exactamente qué cree que está haciendo aquí?' Se lo dije. Estaba buscando alojamiento, me habían hablado de ese pueblo de las montañas y había pensado en pasar la noche allí (2005: 928).

Sadam Husein había llenado el país de chivatos donde todo el mundo tiene un conocido que ha desaparecido o ha sido torturado por criticar al régimen. Francisco Peregil y un periodista belga estuvieron a punto de ser expulsados cuando se adentraron en territorio prohibido para entrevistar a una familia durante la invasión de Irak (2008). En el caso de Laura López para lograr informar sobre una fábrica de cohetes en Oriente Medio tuvo que acceder a ella con los ojos vendados (Bergareche, 2008). Otros informadores recurrieron a la ironía como Ramón Lobo que, cuando salió de Irak con muletas debido a un esguince en el tobillo, dijo en Jordania que era Ronaldo lesionado, les hizo gracia y le dejaron pasar (2007).

Los freelance, periodistas que viajaron al país por su cuenta, ni siquiera contaron con guías del Ministerio puesto que fueron sistemáticamente rechazados por no estar respaldados por ningún medio de comunicación. La embajada iraquí solo estaba interesada en los medios de información solventes, con dinero para pagar los visados y la estancia de los periodistas y, sobre todo, con influencia en la opinión pública (Sistiaga, 2004: 111).

En los cercos de Gaza y Cisjordania, los periodistas tienen que mostrar la acreditación de prensa expedida por el ministerio competente. A pesar de ello, algunos tuvieron que apañárselas para lograr entrar, otros como Mónica G. Prieto consideran que utilizar estrategias no ortodoxas como hacerse pasar por quien no es (escritor en vez de periodista, o humanitario) siempre pasa factura:

En los Territorios Palestinos Ocupados no es necesario hacerse pasar por nada ni emplear ninguna estrategia extraña: basta con el sentido común, la experiencia y los contactos. Sí he tenido que vestir abaya o hijab en sitios como Irak, Chechenia o Afganistán para pasar desapercibida y no ser blanco fácil de controles militares o secuestradores, porque iba sin autorización para trabajar, era un objetivo potencial como extranjera o por alguna otra circunstancia (2008). 
En el cruce de al-Bireh, se dio el caso de dos fotógrafos que intentaron pasar desapercibidos entre la multitud hacia los Territorios Ocupados. Cuando la masa de gente que corría desde el control israelí hacia la ciudad los vio pensó que eran soldados israelíes disfrazados de árabes, ya que no hablaban ni contestaban en ningún idioma. Otros pensaban que eran partidarios de Al Fatah del campo de refugiados de al-Amari, temidos por todos. Luego se dice que quien rescató a los dos fotógrafos era el líder de ese grupo (Hass, 2005: 82).

La obtención de imágenes en directo fue una de las acciones ilegales más penalizadas por los responsables talibán, que solo acreditaron al medio Al Yazira para hacerlo. A pesar de las prohibiciones, algunos periodistas se arriesgaron a filmar imágenes de Kandahar obtenidas de forma clandestina como hizo la cadena CNN. La entrada ilegal en territorio afgano era castigada, consecuencia que vivió la periodista Yvonne Ridley.

Las comunicaciones es otro asunto complicado en las primeras contiendas del siglo XXI. Un punto de inflexión fue la cobertura de Peter Arnett, de la CNN, en la primera Guerra del Golfo, que contaba con un teléfono vía satélite que le permitía emitir directamente. Mientras tanto el resto de periodistas vivió expuesto a las visitas de funcionarios que el Ministerio de Información iraquí había distribuido por todo el hotel con la misión de atrapar infractores. El apoyo de los apparatchiks a sueldo de los periodistas solía prevenirles de la llegada de los guías-espía. Para no correr riesgos Anderson empezó a llevar consigo su teléfono y portátil, cada vez que salía del hotel Al Rashid, lo guardaba en el maletero del coche de Sabah, su taxista (2005: 114).

Los periodistas que llevaron un teléfono vía satélite sólo podían utilizarlo en el Ministerio de Información. Los que pagaron para entrar en las habitaciones del Al Rashid orientadas al sur, que daban acceso al satélite Intermarsat del océano Índico, empezaron a usar clandestinamente sus teléfonos vía satélite. Anderson recuerda que utilizaba su portátil para enviar y recibir correos electrónicos, porque no se fiaba de la cafetería con Internet de abajo. Había un riesgo real en hacer esto, pues les habían dicho que si los pillaban podrían ser expulsados del país. 


\section{Metodología}

En este análisis se utilizaron técnicas cualitativas para obtener información. Las fuentes primarias procedieron de 15 entrevistas en profundidad o no estructuradas centradas sobre la persona con el propósito de conocer sus experiencias vividas. Estas conversaciones profesionales, con un diseño orientado a la investigación social, exigen del entrevistador gran preparación, habilidad conversacional y capacidad analítica (Wengraf, 2001: 4-5). También se tuvieron en cuenta la selección de los entrevistados, el lugar y momento para desarrollar la entrevista y la guía con las preguntas a tratar.

La selección de la muestra fue precisa. Todos los entrevistados tienen solvencia profesional en el ámbito periodístico. Se contó con algunos de los autores de las crónicas seleccionadas: Alfonso Rojo, Gervasio Sánchez y Ángeles Espinosa; dos redactores jefe: Borja Bergareche y Luis Prados; y otros profesionales destacados en la materia como Alfonso Armada, Ana Camacho, Carla Fibla, Carlos García-Santa Cecilia, Francisco Peregil, Ramón Lobo, Mónica G. Prieto, Alfonso Bauluz, Enrique Merino y Felipe Sahagún.

El lugar y el momento de la entrevista fueron elegidos por el entrevistado para así facilitar la realización de la misma. En teoría, el lugar seleccionado debe permitir la grabación sin ruidos, que no tenga connotaciones simbólicas o que no se produzcan interacciones (Callejo, 2009: 79). En seis ocasiones se hizo desde el lugar de trabajo como en el encuentro con Carlos García-Santa Cecilia desarrollado en la Biblioteca Nacional de Madrid. En dos casos, se acudió al correo electrónico debido a la ubicación del periodista fuera de España. Las ocho restantes se desarrollaron en espacios públicos. Los últimos aspectos, también recogidos por María Jesús Merino, fueron las preguntas tratadas a lo largo de la conversación profesional con el entrevistado, que rondaron las dos horas de duración (2010: 48).

Las informaciones secundarias partieron de un análisis de contenido "categorial", donde las unidades de registro se codificaron en categorías, que singularizaron su "contenido". Estas categorías proporcionaron una denominación genérica a unidades de contenido similar, contribuyendo a su clasificación (Cea, 2001: 357). En este estudio se toma la crónica como unidad de registro de la información, que ha de referirse a una de las siguientes categorías: prácticas no ortodoxas, ganarse a las fuentes, salvar la censura, cebos informativos, informaciones indirectas o acceso a las transmisiones. 
En total se analizaron las 25 unidades de registro más significativas de las cinco contiendas. En la Guerra del Golfo, se contaron 11 unidades de registro dentro de las categorías: ganarse a las fuentes (que se repite en la invasión de Irak), salvar la censura, cebos informativos y acceso a las transmisiones. En la Segunda Intifada, se analizaron 5 unidades dentro de la categoría informaciones indirectas. En la "caída" de los talibán se estudiaron 6 unidades dentro de las prácticas no ortodoxas, salvar la censura e informaciones indirectas. Por último, en el caso de la Guerra Civil en Sierra Leona, se observaron 3 unidades incluidas en las prácticas no ortodoxas, ganarse a las fuentes y salvar la censura. En el gráfico 1 se muestra la distribución en cada caso.

\section{Gráfico 1. Unidades de registro y categorías}

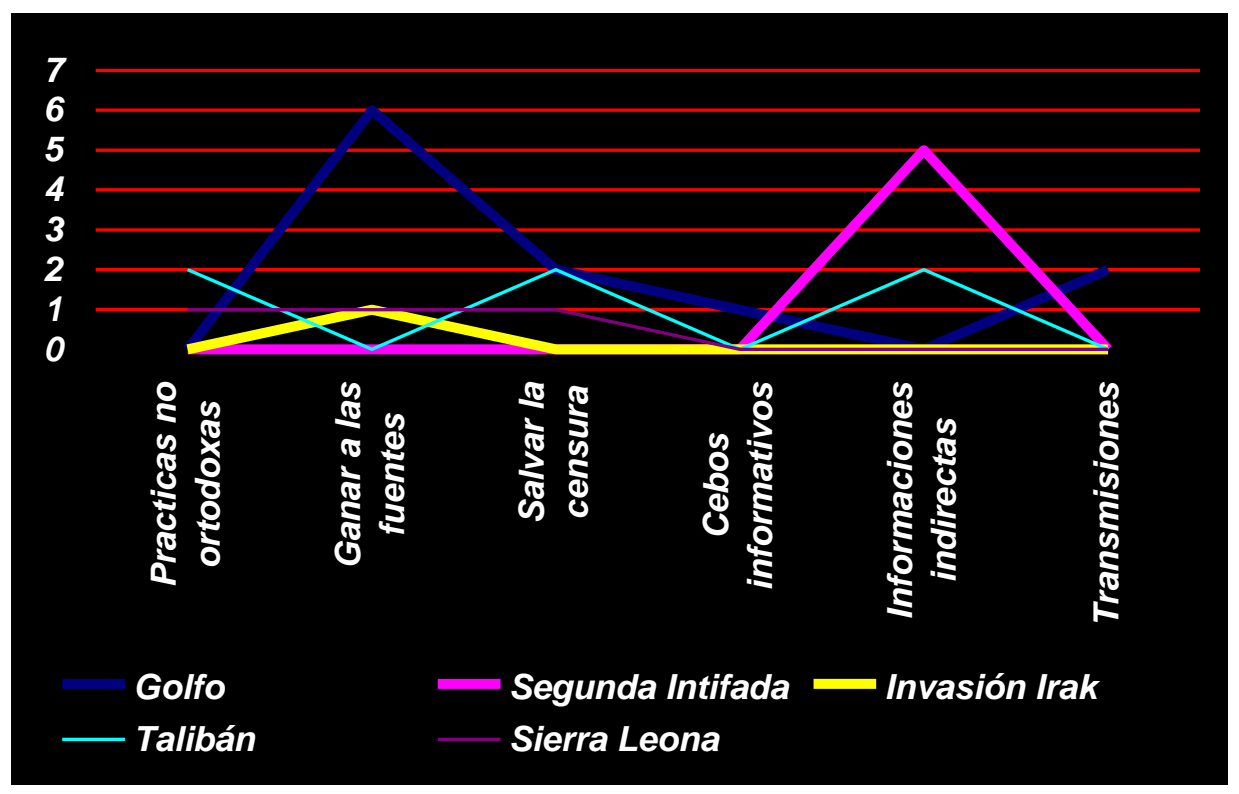

Fuente: Elaboración propia con datos obtenidos

\section{Resultados}

\subsection{Ganarse a las fuentes}

El uso de las bromas, la ironía o los regalos son estrategias muy útiles para acceder a la información. Alfonso Rojo empleó las tres maniobras para acercarse a sus fuentes y que en un momento dado le pudiesen facilitar información. El enviado especial solía aprovechar las 
ausencias de los funcionarios del Ministerio de Información para escabullirse a la calle. En una ocasión, se acercó a la Embajada cubana y antes de desaparecer les comentó en tono festivo que en compensación por la cantidad de agentes que el pasado verano metió Fidel Castro en la Embajada española en La Habana, haciéndoles pasar por refugiados políticos, estaban moralmente obligados, en cuanto la situación se pusiera crítica, a darle asilo en su desconchado edificio (1991: 47).

La ironía le sirvió a Rojo para que le permitieran quedarse en Bagdad hasta el final de la guerra. Entre otras razones, el periodista planteó a Hadizi que con lo oscuro que estaba el hotel, una de esas noches Peter Arnett iba a resbalar y se iba a partir la crisma en las escaleras. Los de Washington les iban a acusar de asesinato y el único testigo que podría corroborar que mister Hadizi era inocente era Rojo (176).

Los regalos a los miembros del Ministerio de Información ayudaron a los corresponsales. Cuando avisaron a los periodistas para abandonar Irak, muchos de ellos hicieron todo lo posible para quedarse, pero no les sirvió de nada. Antes de irse, Rojo regaló las reservas que le quedaban. Cuando Sadún, el jefe del Protocolo le citó para hablar, el reportero pensó que le iba a dar las gracias por el regalo y sin embargo le invitó a quedarse un día más aconsejándole que recogiese su equipaje diciendo al resto que había conseguido otro coche y desaparecer hasta que se fuesen los británicos (59).

Otra "inversión" para contentar a las fuentes consiste en enviar a las personas que fueron entrevistadas o motivo de un reportaje un ejemplar del periódico en el que fue publicada su historia. Alfonso Rojo explica que "algunos se ponen como fieras, pero en la mayor parte de los casos la gente guarda los recortes como oro en paño y la siguiente vez que aterrizas en la zona te tratan como si fueras de la familia". Despedirse dando educadamente las gracias, aunque se hayan portado mal con el periodista también puede servir para una futura cobertura (1991: 311). Rojo no pudo aprovechar los mencionados recursos en la invasión de Irak, ya que en 1991 trabajó desde Bagdad y en 2003, desde el Kurdistán iraquí. Una vez finalizado el conflicto volvió un par de veces a Irak "hasta que decidieron que no volviera más" (2005).

El corresponsal entabló amistad con algunos periodistas como Mohamed Baljí, corresponsal norteafricano del Algerie Actualité. El 29 de enero, comentó que le iba a venir bien tener de aliado a alguien que hablase árabe. Las buenas relaciones de Rojo con los miembros del Ministerio de Información le permitieron cambiar y elegir otro intérprete. El 11 de febrero, narra cómo se decantó por Maruan Ibrajim, porque era más listo, difícil de torear, pero también mucho más encantador y culto. "Como guía-intérprete-espía Fares no estuvo mal, pero me aburría. Era pesado, imprudente y llorón” (201). 
En lo que respecta a las similitudes con las crónicas de la invasión de Irak, destacan los recursos informativos que ya había utilizado en la guerra de 1991. En 2003, mantiene algunos toques de humor como el que empleó para comentar la escasez de norteamericanos en el Kurdistán: "Ayer, acuciados por una necesidad perentoria y a la vista de que el papel higiénico de sus camaradas kurdos era duro como la lija, decidieron enviar a un cabo de compras al mercado" (2003).

En otras ocasiones los periodistas recurren a compañeros para que entretengan a las fuentes y ellos puedan desarrollar su trabajo como Gervasio Sánchez cuando pidió a Alfonso Armada que entretuviese a un montón de niños africanos para poder hacer fotos. El periodista les empezó a cantar y ellos siguieron cada una de sus estrofas con gran interés, de esa forma Sánchez logró hacer fotografías sin ser interrumpido. El primero se sintió como "el flautista de Hamelín", pero "gracias a esa estrategia, el fotoperiodista pudo hacer las fotos tranquilo" (Armada, 2002: 88).

Ramón Lobo cuando llegó a Sierra Leona con Gervasio Sánchez se puso a jugar al fútbol o bañarse con los niños para ganar su confianza. Lobo funciona con el lenguaje corporal, trata de transmitirles que viene de muy lejos y tiene mucho tiempo para escuchar sus historias: "Me gusta ponerme en el lugar del otro, tengo una enorme empatía, me gusta sacar información. Esta actitud forma parte de mi, incluso al margen del trabajo" (2007).

\subsection{Salvar la censura de los guías-espías}

En la mayoría de los conflictos, el desconocimiento del idioma local hace que los periodistas tengan que depender de los intérpretes, normalmente de los llamados espías-traductores que en la mayor parte de los casos responden de igual forma a los testimonios de la población civil. Los periodistas tienen que aprovechar la ausencia de los intérpretes-espías para ponerse en contacto con las fuentes. Un ejemplo, lo vivió Alfonso Rojo un día de jaleo, en el que Marun, su intérprete, se alejó del teléfono, que aprovechó para contarle a John Müller los párrafos censurados que le habían impedido enviar al periódico (1991: 232). En otra ocasión, Rojo se valió de la ausencia de Fares para interrogar a Karim, un traductor ingenuo que le permitió trabajar con soltura y enviar crónicas más comprometidas. Ese día Fares desconfió de la actuación del corresponsal y decidió que debía salir del país (131).

Durante otra ausencia de su traductor, el periodista también enseñó la crónica a Mohamed, un estudiante de español que probablemente colaboraba con la policía secreta. En circunstancias normales hubiera tenido que tratar con Maruan, ajustando cuidadosamente las palabras y eliminando referencias militares. Con Mohamed comenzó la nota con el 
victorioso comunicado 62 y metió después todo, desde la frase del holandés misterioso hasta los datos cazados al vuelo en la habitación de Pazaluk. La estratagema le funcionó, al cabo de diez líneas lo único que recordaba Mohamed era el comunicado militar, que a la hora de transmitir se encargó Rojo de bajar a mitad de la crónica, justo detrás de la frase en la que el soviético cuestionaba la veracidad de los partes de guerra (276).

El hecho de ser occidental y salir por el mercado con un cuaderno en la mano ayuda a obtener información porque la gente siente curiosidad y en seguida se forma un corrillo. El problema se da cuando se desconoce el idioma y no se puede hablar con cualquier fuente. Esto dificulta la labor informativa de los periodistas, puesto que tienen que valerse y fiarse constantemente de sus traductores, muchas veces impuestos por el gobierno de turno.

En Irak todos los periodistas estaban obligados a inscribirse en el Ministerio de Información, allí les asignaban intermediarios nombrados oficialmente para solicitar entrevistas, obtener permisos de viaje y renovaciones del visado. Salvo raras excepciones, los visados duraban sólo diez días y, en consecuencia, había que dedicar parte de cada visita a intrigar, untar y congraciarse con funcionarios del ministerio para que ampliasen el visado. En el caso de Anderson, Sabah, su taxista, se tomaba muchas molestias para asegurarse de que no tuviera que pagar sobornos en efectivo, y al final de su primer viaje, por ejemplo le sugirió que comprase tres cajas de Pepsi para el jefe de la oficina de prensa extranjera, y dos cajas de Seven-Up para su asistente, que Sabah le confesó que en realidad era un agente del Mujabarat (2005: 86).

Los traductores-espías organizaron viajes que limitaron la necesidad de información de los reporteros, no obstante, algunos lograron despistar a los funcionarios para dirigirse a otros lugares. Espinosa cuenta cómo ella, Masegosa y Baquero aprovecharon un descuido para despistar al grupo y dirigirse a la Embajada siria, donde conocían al embajador Mohamed Hasan Tawab. Los trayectos en coche también fueron decisivos para grabar algunos lugares prohibidos en pleno recorrido:

"Nuestro esfuerzo por reportear se ve compensado con detalles muy ilustrativos: el bloqueo en los puentes, el nerviosismo de los milicianos y, ahora, en el barrio de Adhamiya, un potente misil Al Samud escondido en un vivero de plantas" (2003: 163).

Los funcionarios solo les permitieron pasar por aquellos sitios que les interesaban, el resto estaba prohibido para los corresponsales. Normalmente imponían las prohibiciones con la excusa de mantener la seguridad de los periodistas que estaban apostados en la capital 
iraquí. En una ocasión se produjo un daño colateral en el que la aviación estadounidense mató a cuarenta y ocho civiles e hirió a más de trescientos en la ciudad de Hilla, y solo les dejaron ver el cráter de la universidad. Únicamente se pudieron hacer una idea de la masacre cuando el enviado del France Presse, Jacques Charmelot la narró (114). En la invasión de Irak tampoco contaron con visitas al frente, encuentros con soldados en primera línea, entrevistas con Sadam Husein, Uday o Qusay Husein.

Gervasio Sánchez recuerda las mentiras de los traductores. Al igual que Corinne Dufka y Carla Fibla para contrarrestar ese peligro indica que busca gente de confianza y le pedía al traductor que le transcriba literalmente lo que escuchaba, sin permitirle hablar (2007). Cuando los periodistas desconfían de la traducción literal, suelen grabar la entrevista. Carla Fibla tiende a contrastar la grabación con otra persona. En Argelia le pareció que un traductor ponía cosas de su cosecha, la corresponsal pidió ayuda a una amiga, que le confirmó sus sospechas. "Los testimonios tienen que ser ciertos, sobre todo en la radio" (2008).

El uso de los idiomas para poder intercambiar información sin que los traductores o los taxistas se enterasen fue otra de las tácticas empleadas por los periodistas. Rojo y Christoph emplearon esta práctica con un taxista para dialogar sobre Irak: "-¡Alí! Toi tu connais Paris?" Al no responderle, ambos pudieron intercambiar reflexiones (182).

La dificultad para comunicarse con algunos testigos de la crisis afgana hizo que Ángeles Espinosa recurriese a la correspondencia para obtener algunas informaciones relevantes, situación que vivió con un testigo directo de la guerra que prefirió mantenerse en el anonimato. Otras entrevistas las tuvo que rematar por teléfono ante la imposibilidad de citarse personalmente con fuentes poco accesibles como le ocurrió con Ahmed Wali Karzai, quien habló con ella vía telefónica desde Quetta.

Desde el Ministerio de Información añadieron una lista con las regulaciones que debían seguir los corresponsales de guerra que trabajaran en Bagdad durante la invasión de Irak de 2003. La censura "no se rebajó en absoluto", "simplemente se modificó el ejercicio de la misma” (Sahagún, 2007).

En el Ministerio se publicaba el Iraq Daily de Nasra al Sahún, así como folletos y panfletos que contenían los discursos de Sadam y la posición de su gobierno sobre cuestiones tales como "embargo o genocidio", "la política norteamericana de doble rasero" o "crímenes norteamericanos contra Irak". En el ministerio, sede de la oficina de prensa extranjera, se celebraban casi todas las conferencias de prensa oficiales. 
Una serie de agencias de prensa internacionales, en su mayoría servicios de teletipo, fueron autorizadas a alquilar despachos y a contratar personal en dicha oficina. Solían ser periodistas iraquíes o árabes que sabían operar dentro del sistema o bien eran, en realidad, empleados del ministerio que hacían tejemanejes a sueldo de diversas organizaciones de medios de comunicación. La CNN había conseguido un trato especial años antes. Anderson añade que desde hacía mucho era la única cadena de televisión norteamericana que estaba autorizada a tener en Bagdad un corresponsal y una oficina permanente (2005: 87).

En el centro de prensa era fácil acceder a la BBC y la CNN, sus operadores controlaban continuamente sus emisiones, así como las de Al Yazira, que emitía desde su propio chalet cercano. Sin embargo, para el resto de los iraquíes la televisión estaba prohibida, tenían que conformarse con alguna de las dos cadenas de televisión estatales, que consistían en noticias oficiales abreviadas, viejas películas egipcias en blanco y negro, y reposiciones de Sadam (87).

Algunos periodistas equipararon estas medidas con la actuación de los estadounidenses, sólo que en Irak como apunta Esteve de TV3 los periodistas pagaban 125 dólares diarios por los servicios del Centro de Prensa, a los que tenían que sumar 100 dólares diarios por la tenencia y uso del teléfono por satélite.

En Estados Unidos, controlaron los medios de comunicación en lo que se refiere a sus contenidos. Las emisoras de una de las tres grandes cadenas de televisión estadounidenses recibieron un documento de mil quinientas páginas con instrucciones para "modular" el contenido del mensaje y sus fuentes en la invasión de Irak. A los periodistas televisivos con base en Bagdad les dijeron que sus reportajes llevarían la advertencia de que sus informaciones habían sido controladas por las autoridades iraquíes. "Controladas" significaba "censuradas", aunque en muchos casos no fue cierto.

En otras ocasiones, fueron las propias cadenas de televisión y emisoras de radio las que ejercieron la autocensura. Las instrucciones que emitió la CNN en enero de 2003 son muy clarificadoras al respecto:

"Todos los periodistas que preparen paquetes de noticias deben entregar las noticias para su aprobación. Los paquetes no serán editados hasta que las noticias se hayan aprobado. Todos los paquetes que se redacten fuera de Washington, LA, NY, incluidas todas las oficinas internacionales, deben pasar por la MESA (mesa de editores de Atlanta) para ser aprobados" (Fisk, 2005: 1290). 
La autocensura de los medios de comunicación y el uso que de ellos hicieron los distintos gobiernos hizo que, tras la invasión de Irak, se les recordara, sobre todo los estadounidenses, por utilizarlos para transmitir la propaganda del país produciendo un daño irreparable a la prensa. Tortosa añade que la credulidad ante tal propaganda no es solo producto de su profesionalidad sino también de la pereza mental de los públicos y audiencias (2004: 176).

El informe de Reporteros sin Fronteras de junio de 2003 indica que los periodistas iraquíes también se impusieron a sí mismos una especie de autocensura para no incomodar a los mandos militares de EE.UU. o a los dirigentes políticos iraquíes" (Gutiérrez de Terán, 2006: 138). Otros reporteros iraquíes publicaron informes propagandísticos a favor del ejército americano. Mediante esta actuación, "el Gobierno estadounidense trató de humillar a la prensa nacional independiente comprando a un puñado de advenedizos recién arrimados a la profesión con el objeto de influir sobre la prensa y combatir a los medios de comunicación nacionales" (140).

El Ministerio de Información iraquí facilitó propaganda falsa a los periodistas a modo de montajes, luego estos tuvieron que editar la información de manera que los funcionarios se quedaran contentos y a la vez el reportero no se traicionara a sí mismo. En una ocasión, los funcionarios hicieron creer que habían caído unos paracaidistas británicos al Tigris ofreciendo recompensa a quien los capturara vivos o muertos. Algunos periodistas aprovecharon para dar la noticia sin haber visto a ningún militar británico, práctica del Ministerio de Información que Sistiaga califica de "operación cosmética": "De un ministerio que también podíamos llamar de desinformación, agitación o propaganda. De un ministerio creado expresamente para manejar la información como si fuera una materia de Estado" (2004: 108-238).

Asimismo, el gobierno iraquí presionó a los medios de comunicación extranjeros, en especial árabes, como a la televisión vía satélite al-Yazira, de Qatar, a cuyos corresponsales se les prohibió durante meses cubrir las noticias dentro de Irak. "Para las autoridades iraquíes, alYazira y otros medios de comunicación aportan cobertura y difusión informativa a los grupos terroristas y los partidarios de Sadam Husein. Para los responsables de la cadena, sus periodistas se limitaban a cubrir los acontecimientos más relevantes y trasladar a sus espectadores imágenes de las acciones militares en las áreas de mayor conflictividad" (Gutiérrez de Terán, 2006: 137).

A la censura se sumó la posible expulsión del país en cualquier momento, como les ocurrió a los periodistas en la guerra del Golfo de 1991. En la invasión de Irak, los reporteros se enteraban cada cierto tiempo que habían amenazado a algún compañero con echarlo del 
país. Alfonso Rojo afirma que aunque disminuyó la censura durante la invasión cada vez que los periodistas renovaban el visado tenían que agradar a los censores para que no los expulsaran (2005).

\subsection{Cebos informativos}

Una buena estrategia para informar consiste en pasar desapercibido, dejar barba, vestir menos occidental, mantener la boca cerrada o no identificarse como periodista. Algunos reporteros se pusieron un burqa o se hicieron los sordomudos para que nos los reconocieran. Francisco Peregil consiguió pasar por pakistaní con un turbante en la cabeza, se montó en un coche y logró una crónica desde Spin Boldak (2008). Gervasio Sánchez se dejó crecer la barba en Bagdad para infiltrarse como iraquí. En la calle, encontró una pareja "haciendo manitas". Con la ayuda de su testimonio y los de otras parejas, elaboró el reportaje "El amor en los tiempos de guerra" (2007).

Peor suerte corrió Michel Peyrard, enviado especial de París Match, detenido en Gohta, en la carretera que va de la frontera pakistaní a Jalalabad, oculto en un burqa y con otros dos guías pakistaníes. Los tres fueron exhibidos por las calles de esa ciudad y apedreados por la multitud antes de ser acusados de espionaje a favor de Estados Unidos (Leguineche, 2001: 144).

En otras ocasiones, los periodistas no identifican su profesión con el propósito de pasar inadvertido. Enrique Merino a veces se presentaba como una persona de la calle o familiarizada con alguien:

"Cuando me enteraba de cosas y al final me preguntaban por qué me informaba tanto, entonces me identificaba como periodista, pero el 'daño' ya estaba hecho, ya había obtenido la información que quería. Si de primeras me preguntaban si era periodista, siempre respondía afirmativamente. En otras ocasiones, es mejor y más productivo y seguro identificarse como periodista, en otras no. Depende" (2007).

En el caso de la guerra civil sierraleonesa, no fue tan fácil camuflarse ni entrevistar a las fuentes debido a la ofensiva de la guerrilla (2007). El día de la crónica sobre la liberación de Javier Espinosa, en una información de Rogelio Alonso desde Belfast, el Heraldo de Aragón recoge la violación de los principios fundamentales por parte la BBC a la hora de hablar de la guerra civil sierraleonesa. La BBC no se ocupó del país hasta que emitió un reportaje donde 
afirmó que su corresponsal Mark Doyle había sido el primero en entrar en el país después de que los periodistas españoles llevaran varias semanas informando del conflicto.

Cuando el Heraldo contactó con el programa para cuestionar la línea editorial de la crónica de Doyle, un periodista le pidió disculpas por la omisión de los enviados especiales españoles, justificándola de la siguiente forma: "La situación en África es muy complicada y la historia del secuestrado (Javier Espinosa) se convierte en un detalle que para la audiencia británica carece de interés". Tras este hecho, los miembros del periódico español descubrieron por medio de otra periodista, la cual prefirió mantenerse en el anonimato, que "la cobertura de Sierra Leona fue sometida a restricciones". Motivo por el que El Heraldo aprovechó la crónica de Alonso para cuestionar los principios de la BBC.

Alfonso Rojo confiesa que también utilizó un cebo informativo con el coronel Víctor Pazaluz en la Guerra del Golfo con el fin de conocer la situación de Irak a través de las informaciones del experto soviético. Para despertar el interés del experto militar, le dice que "-los de las televisiones americanas hablan cada noche con Washington y dicen que han tirado paracaidistas en Naseriya-. No parece una bola... Al coronel soviético se le iluminan los ojos. Cambia el gesto y me invita a su pequeño estudio al fondo del patio" (1991: 271).

\subsection{Informaciones indirectas}

Las informaciones indirectas provienen de otros medios de comunicación como las conferencias, las ruedas de prensa o los comunicados de prensa a los que puede tener acceso el periodista.

En la "caída" del régimen talibán, la mayoría de los comunicados de prensa que recogió Ángeles Espinosa partieron de la embajadas de Afganistán en Pakistán o del Ministerio de Asuntos Exteriores, Juan Cierco se sirvió de distintos agentes implicados en el conflicto como: La oficina del primer ministro israelí, el Departamento de Estado norteamericano, la ANP, Al Fatah o el gabinete de seguimiento de Israel, entre otros.

En lo que respecta a las ruedas de prensa también partieron de distintos actores del conflicto entre los que se encontraron una sesión especial de emergencia de la Asamblea General de la ONU o una rueda de prensa del primer ministro israelí Ehub Barak.

El interés de las autoridades locales a que los periodistas asistieran a una rueda de prensa diaria se reflejó en la cantidad de veces que Ángeles Espinosa hizo uso de este recurso. Lo que implicaría una de las dos vías que se trasladan desde el punto 1.14 del "Libro de estilo 
de El País": las informaciones de que dispone un periodista pueden ser obtenidas por su presencia en el lugar de los hechos o la narración por una tercera persona (1990: 17).

\subsection{Prácticas no ortodoxas}

En las zonas en conflicto se hace difícil entrevistar a las fuentes de información. En algunos casos los enviados especiales recurren a la extorsión para sacar información de aquellas que todavía tienen libertad de maniobra. El soborno es el mejor de los "trucos informativos" en las guerras (Prados, 2007). "Normalmente cuando pretendes pasar a un sitio o informarte y hay dos soldados jóvenes cortándote el paso, se podría solucionar con un frase del tipo: ¿Os ayudaría a recordar 100 dólares?" La corrupción oficial era un hecho cotidiano en Irak, "sin pagar sobornos no podías trabajar" (Anderson, 2005: 238).

En situaciones de peligro, valen todas las estrategias siempre y cuando no perjudiquen a otra persona. En Afganistán, los periodistas tuvieron que desembolsar dinero por todo para no correr riesgos. Los periodistas tenían que pagar por un guardaespaldas, por un conductor y dependiendo del área en la que se encontraran, podían estar bajo el dominio de un caballero de la guerra, que tomaría una parte (Hess, 2003: 180).

Alfonso Armada no recuerda haber pagado con dinero, suele llevar tabaco, "te abre muchas puertas". Sobre todo, recurre a la estrategia del humor. Cuando se enfrenta con soldados jóvenes armados, bebidos o drogados es muy difícil controlar la situación porque son muy imprevisibles. "Tienes que mantener la calma, no perder el humor, tratar de ganártelos. El humor, la forma de manifestarte ayuda mucho. Las estrategias humanas, de mirar a los ojos, no hacer movimientos bruscos, no tratar de engañarlos o buscar la complicidad a través del tabaco" (2007). En Etiopía y Guinea Ecuatorial, Ana Camacho regalaba libros para que le permitiesen transmitir alguna crónica sin que se enterasen los traductores (2008).

En la guerra del Golfo cuando el ejército aliado comenzó a bombardear Bagdad el 17 de enero de 1991, Alfonso Rojo y Juan María Calvo plantearon la posibilidad de extorsionar y engañar a varios policías para conseguir sus objetivos. En cuanto sonase el primer disparo, llegaron a la conclusión de que deberían salir para la embajada, "darle un billete de cien dólares al asustado soldado de la garita, dos, tres, cuatro... los que hicieran falta... forzar la puerta de un patadón”. En caso de que tuviesen problemas siempre podrían justificar el asilo por pura necesidad. Los dos reporteros también se plantearon la posibilidad de entrar en el hotel Meliá al Mansur engañando a los policías armados que montaban guardia en el portón diciéndoles que eran del Chinese restaurant (Rojo, 1991:21). 
La escasez de información hace que abunden los rumores que algunos periodistas recogen en sus crónicas. En la guerra contra los talibán, Ángeles Espinosa incluyó algunas informaciones que no partieron de fuentes identificadas porque, según indica, "el mundo está lleno de rumores. Por eso tenemos trabajo los periodistas, para separar el trigo de la paja" (2006). Un ejemplo se dio el 21 de septiembre de 2001: "Los rumores de que los talibán están reclutando forzosamente a los jóvenes no hará sino incrementar esa cifra en los próximos días". En la Guerra Civil sierraleonesa, Gervasio Sánchez empleó sus propias fuentes de información y sólo recurrió a la rumorología cuando habló de los análisis sobre una mayor implicación de los soldados ingleses en el conflicto de Sierra Leona (2000). El resto de sus informaciones contaron con fuentes identificadas.

La falta de información hace que algunos reporteros mezclen distintos datos. Para Luis Prados "eso no son trucos, eso es estafar. Un truco es algo personal. Una periodista podría ir con unas amigas a un sitio de difícil acceso y engatusar al chico de la entrada para que las dejase pasar, lo que nunca podría hacer después sería mentir o copiar" (2007). En la caída de los talibán, la escasez de datos condujo a Ángeles Espinosa a recomponer la información a través de varios relatos como hizo en la crónica del 29 de octubre de 2001. La falta de confirmación de las informaciones directamente por parte de los entrevistados hizo que la periodista emplease su medio para contar al lector los problemas que le surgieron, como hizo en la crónica del 11 de noviembre: "Esta informadora trató sin éxito de aclarar esa discrepancia con el autor de la entrevista, pero fuentes de su periódico insistieron en que no había diferencia".

Internet también fue un instrumento para transmitir noticias falsas que fueron aceptadas "sin rechistar" por algunos medios. $Y$ rumores dados por buenos sin consultar las fuentes. Leguineche recoge varios ejemplos: "Los talibanes habrían desplegado misiles Scud en la frontera con Pakistán: mentira. Las manifestaciones en Peshawar e Islamabad eran 'impresionantes'. El país estaba en vísperas de una revolución. Mentira" (2001: 153). La dificultad para clarificar una información o identificar la procedencia de la misma quedó patente en la crónica del 8 de octubre de 2001, donde Espinosa cuenta que "todo el fin de semana hubo rumores...".

El "Libro de estilo de El País" no deja lugar a dudas en el punto 1.13., donde afirma que los rumores no son noticia: "Cuando el rumor sea utilizado por alguna persona o grupo como arma arrojadiza contra otro, se podrá denunciar este hecho, pero sin citar las acusaciones difundidas mediante esa argucia" (1990: 17). 
En Ruanda, por el contrario, muchos enviados especiales se limitaron a informar empleando, en ocasiones, estrategias no ortodoxas. El periodista Fernando Olmeda recuerda cómo allí conocieron reporteros que vieron a una persona moribunda en una cuneta y le tomaron una fotografía o para enfocar adecuadamente se apoyaron sobre el cuerpo muerto o agonizante de una niña (2007: 213).

La falta de respeto hacia las víctimas sumada a las malas artes de algunos periodistas famosos que fastidiarían a sus compañeros sin contemplaciones, desvirtúa la labor de los reporteros. Gervasio Sánchez afirma que a estos reporteros sólo les interesa su currículum, por lo que utilizan su trabajo para hacerse famosos o ganar premios (2007). Corinne Dufka matiza que, por lo general, los corresponsales están más movidos por el sufrimiento de las víctimas llegando a arriesgar sus vidas para evacuar civiles heridos o dar dinero y comida para ayudar a familias hambrientas.

En Sarajevo, Armada y Sánchez vivieron una situación muy comprometedora cuando entrevistaron en un hospital a unas mujeres violadas musulmanas bosnias con mucha tranquilidad, calma y delicadeza. Alfonso Armada se puso a hacerles fotos de espaldas para que no saliera su cara. Cuenta que había una intérprete, una mujer que hizo que el acercamiento fuera más cercano:

"Es fundamental el respeto, huir del atosigamiento que ves en algunos medios, especialmente con noticias que no son tales, con montajes que se organizan en torno a un personaje famoso, esa degradación de la prensa, sobre todo, en programas de televisión" (2007).

Otra práctica no ortodoxa que se utilizó en África consiste en el fenómeno conocido como "el periodismo chantajista" descrito por Amadu Wurie Khan, periodista de Sierra Leona, donde los redactores amenazan con escribir datos falsos y despectivos de la gente a no ser que se les pague determinada cantidad; otras pruebas sugieren que esta y otras formas de corrupción son prácticas muy extendidas en la prensa africana:

"De este modo, la libertad de expresión, aunque quizá se trate del cambio más duradero incluido en las reformas políticas entre 1989 y 1992, en la realidad no garantiza ni la democracia, ni la calidad de la información, ni el debate político razonado a pesar de las esperanzas que depositaban en ella los gobiernos que la respaldaron" (Leguineche, 2001: 411). 


\subsection{Acceso a las transmisiones}

Otro de los problemas que tuvieron que superar los reporteros fue la dificultad para realizar las transmisiones con la redacción. En la guerra de 1991, Alfonso Rojo se sirvió de su amistad con Sadún para conseguir que los de la CNN le dejasen utilizar el satélite. El jefe del Protocolo insistió en que no había problema y más tarde le hizo la gestión (1991: 68). Bernard Estrade también le permitió utilizar el teléfono de la AFP para enviar sus crónicas alegando que con el tiempo que el corresponsal español llevaba en Irak iban a tratarle como si fuera francés.

El 31 de enero de 1991, Rojo contó una de las triquiñuelas que tuvo que hacer para enviar su material fotográfico al diario El Mundo. El enviado especial y el fotógrafo ruso Igor le pidieron a William Brown, veterano de Vietnam y amigo de Sadam Husein, que les llevase los rollos de película y todas las fotos tomadas desde el inicio del conflicto a sus respectivos medios. Más adelante descubrieron que Brown había utilizado todo ese material en beneficio propio.

Durante la invasión de Irak de 2003, para que no se los confiscaran los teléfonos por satélite los escondieron en la habitación, por ejemplo, en cajas de cartón de comida preparada del ejército o en el rodapié de una de las camas que estaban utilizando como escudos contra las explosiones. Jon Lee Anderson acabó agotado por tener que permanecer despierto, ya que necesitaba usar los teléfonos para comunicarse con su editor y familia. Además contaba con un sistema de transmisión con otros reporteros en habitaciones cercanas, y a través del teléfono del hotel con los distintos pisos para avisar si llegaba algún agente de seguridad (2005: 232).

Cuando les permitieron volver a usar los teléfonos por satélite desde el Ministerio de Información, Anderson lo instaló dentro de una caja de leche de plástico amarillo, sobre una cornisa debajo del pretil del balcón apoyando la antena plana en el ángulo correcto para captar el satélite Inmarsat en el Atlántico este.

Tras los bombardeos al Ministerio de Información, este se convirtió en un lugar inaccesible para la prensa. Los reporteros que salieron por su cuenta y riesgo a inspeccionar la destrucción a la mañana siguiente del segundo ataque aéreo fueron sumariamente expulsados de Irak como le ocurrió a uno australiano y otro sudafricano. Para entonces muchos comprendieron lo que estaba ocurriendo de verdad y acosaron sin rodeos a sus escoltas para que los llevaran al aeropuerto, cuyo control afirmaban ahora que habían recuperado. Durante las incursiones, el hotel Al Rashid se volvió un lugar inseguro y probablemente lleno de micrófonos en todas las habitaciones. Para evitar este problema y 
disponer de otras alternativas Anderson alquiló habitaciones en el Al Safeer y el Al Hamra (160).

A pesar de estos riesgos, los periodistas tuvieron que enviar toda la información posible a sus redacciones con el permiso de algún miembro del ministerio para que desprecintase el teléfono. Avisados los enviados especiales que llegaron nuevos procuraron traer varios teléfonos satélites para llevar uno escondido al pasar por el aeropuerto, de ese modo poder utilizar sin censuras el que no fuera confiscado (Sistiaga, 2004: 110 y 118).

\section{Conclusiones}

De las cinco contiendas analizadas se desprende el uso generalizado de los recursos tendentes a ganarse a las fuentes a través de diversas "inversiones". El uso de las bromas, las ironías, los regalos o la amistad de los periodistas con el personal de los hoteles, les ayuda a lograr los favores de las posibles fuentes de información en la mayoría de los casos. En especial, el trato de respeto aunque no se hayan portado bien con el periodista o el envío a sus casas de material publicado en el medio puede facilitarles futuras entrevistas.

En el mismo porcentaje se encuentran las informaciones indirectas a las que recurren con bastante asiduidad. Los datos que se suele trasladar en estas guerras parten en el $90 \%$ de los casos de las fuentes oficiales entre las que se encuentran las embajadas, las oficinas de información de los bandos enfrentados o incluso los distintos actores internacionales como la ONU.

El problema más habitual con el que se encontraron los reporteros fue la censura, en especial, la de los guías-espías del régimen de Sadam Hussein que seguían sus pasos. Los periodistas aprovecharon la ausencia de los intérpretes para salir en busca de fuentes de información no oficiales o trasladar sus crónicas a las redacciones. El uso de otro idioma desconocido para los espías también facilitó a los periodistas comunicarse con sus compañeros. El mejor procedimiento consistió en no permitir hablar a los traductores, que se limitasen a trasladar lo que decían las fuentes y hacer una posterior confirmación de lo grabado.

En algunas circunstancias la presión sobre los reporteros se hizo tan insostenible que para acceder a ciertas informaciones tuvieron que acudir a prácticas no ortodoxas o cebos informativos con el propósito de obtener datos relevantes. El uso de fuentes no identificadas, la recomposición de la información a través de diversos datos, la rumorología o despertar el interés de algún entrevistado para sacarle información también formó parte de la metodología empleada por los cuatro periodistas. 
Todas estas habilidades en mayor medida lícitas no hubieran servido de nada si finalmente el periodista no hubiera logrado contactar con su redacción. La amistad con miembros del Ministerio de Información o con colegas de la profesión, les facilitó el acceso a las transmisiones, sobre todo, durante la Guerra del Golfo. En el resto de contiendas las dificultades fueron menores.

En conclusión, el acceso a las fuentes en las zonas en conflicto se hace posible gracias a las habilidades que despliegue el periodista en el momento de entrevistarlas y cómo eluda la censura de los guías-espías. La obtención de la información ha de completarse con su envío a la redacción correspondiente. El binomio acceso y transmisión de la información ha de llevar implícito una buena dosis de talento, paciencia y buen hacer periodístico.

\section{Bibliografía}

Anderson, Jon Lee. (2005): La caída de Bagdad. Barcelona: Editorial Anagrama.

Armada, Alfonso. (2002): Cuadernos Africanos. Barcelona: Ediciones Península.

Callejo, Javier (coord.) (2009): Introducción a las técnicas de investigación social. Madrid: Editorial centro de estudios Ramón Areces.

Cea, M. Ángeles. (2001): Metodología cuantitativa. Estrategias y técnicas de investigación social. Madrid: Editorial Síntesis.

Dray, Joss y Sieffert, Denis. (2004): La guerra israelí de la información. Desinformación y falsas simetrías en el conflicto palestino israelí. Madrid: Ediciones del oriente y del mediterráneo.

El País, libro de Estilo (1990): Libro de Estilo de El País. Madrid: Ediciones El País.

Espinosa, Ángeles; Masegosa, Alberto; Baquero, Antonio. (2003): Días de guerra. Madrid: Siglo XXI de Editores.

Fisk, Robert. (2005): La gran guerra por la civilización. La conquista de Oriente Próximo. Barcelona: Ediciones Destino.

Hass, Amira. (2005): Crónicas desde Ramala. Una periodista en territorio ocupado. Barcelona: Galaxia Gutenberg. Círculo de Lectores. Traducción de José Luis Gil Arista.

Hess, Stephen; Kalb, Marvin editors. (2003): The media and the war on Terrorism. Massachussets Avenue: The Brookings Institution. 
Hijazy, Ahmed; Vargas, Oscar-René; Alami, Said; Saleh, Waleed; Sadoun, Addul H.; Montiel, Fernando; Gutierrez de Terán, Ignacio. (2003): Irak: Un mar de mentiras. Madrid: Ediciones Olivum.

Leguineche, Manuel. (2001): Recordad Manhattan. El 11 de septiembre. Afganistán. La guerra. Guadalajara: Editorial Maori.

Olmeda, Fernando. (2007): Gerda Taro, fotógrafa de guerra. El periodismo como testigo de la historia. Barcelona: Editorial Debate.

Rojo, Alfonso. (1991): Diario de la guerra. Barcelona: Planeta.

Sánchez, Gervasio. (2004): Salvar a los niños soldados. La historia del misionero Chema Caballero en Sierra Leona. Barcelona: Debate.

Sistiaga, John. (2004): Ninguna guerra se parece a otra. Barcelona: Plaza y Janés.

Tortosa, José María. (2004): La guerra de Irak: un enfoque orwelliano. Alicante: Publicaciones Universidad de Alicante.

Wengraf, Tom. (2001): Qualitative Research Interviewing. London: SAGE Publications Ltd Zaccara, Luciano; Saleh, Waleed; Iglesias, Alfonso; Gutiérrez de Terán, Ignacio (coord.) (2006): Irak. Invasión, Ocupación y caos. Madrid: Catarata.

\section{Entrevistas}

- Armada, Alfonso. (2007): Entrevista en Madrid, 30 de octubre.

- Camacho, Ana. (2008). Entrevista en Madrid, 2 de abril.

- Bauluz, Alfonso. (2008): Entrevista en Madrid, 9 de diciembre.

- Bergareche, Borja. (2008). Entrevista en Madrid, 23 de octubre.

- Espinosa, Ángeles. (2006): Entrevista en Madrid, 14 de junio.

- Fibla, Carla (2008): Entrevista en Madrid, 4 de abril.

- G. Pietro, Mónica (2008): Entrevista en línea, 11 de octubre.

- García-Santa Cecilia, Carlos. (2008): Entrevista en Madrid, 5 de febrero.

- Lobo, Ramón. (2007): Entrevista en Madrid, 29 de diciembre.

- Merino, Enrique. (2007): Entrevista en línea, 1 de diciembre. 
- Perejil, Francisco. (2008): Entrevista en Madrid, 13 de febrero.

- Prados, Luis. (2007): Entrevista en Madrid, 23 de marzo.

- Rojo, Alfonso. (2005): Entrevista en Molina Seca, León, 9 de mayo.

- Sánchez, Gervasio. (2007): Entrevista en Madrid, 10 de octubre.

- Sahagún, Felipe. (2007): Entrevista en Madrid, 8 de noviembre.

\section{Forma de citar este artículo en bibliografías}

FUENTES FERNÁNDEZ, R. (2011): "Acceso y transmisión de la información en las primeras guerras del S.XXI", en Revista PANGEA, 2, páginas 92 a 115. Red Académica Iberoamericana de Comunicación. Recuperado el _ de de_ de 2 __ de: http://revistapangea.org 